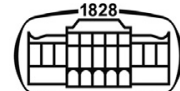

AKADÉMIAI KIADÓ

\title{
Functional assessment of coronary plaques using CT based hemodynamic simulations: Current status, technical principles and clinical value
}

\section{IMAGING}

\section{REVIEW ARTICLE}

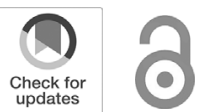

IMAGING 13 (2021) 1, 37-48

DOI: $10.1556 / 1647.2020 .00011$

(c) 2020 The Author(s)

${ }^{*}$ Corresponding author.

Tel.: +3620666 3857

E-mail: melinda.b.md@gmail.com

\section{AKJournals}

\author{
MELINDA BOUSSOUSSOU ${ }^{1 *}$, BORBÁLA VATTAY ${ }^{1}$, \\ BÁLINT SZILVESZTER ${ }^{1}$, MÁRTON KOLOSSVÁRY ${ }^{1}$, \\ JUDIT SIMON ${ }^{1}$, MILÁN VECSEY-NAGY ${ }^{1}$, \\ BÉLA MERKELY ${ }^{1}$ and PÁL MAUROVICH-HORVAT ${ }^{1,2}$ \\ ${ }^{1}$ MTA-SE Cardiovascular Imaging Research Group, Heart and Vascular Center, Semmelweis \\ University, Budapest, Hungary \\ ${ }^{2}$ Department of Radiology, Medical Imaging Centre, Semmelweis University, Budapest, Hungary
}

Received: August 13, 2020 • Accepted: November 26, 2020

\begin{abstract}
In recent years, coronary computed tomography angiography (CCTA) has emerged as an accurate and safe non-invasive imaging modality in terms of detecting and excluding coronary artery disease (CAD). In the latest European Society of Cardiology Guidelines CCTA received Class I recommendation for the evaluation of patients with stable chest pain with low to intermediate clinical likelihood of CAD. Despite its high negative predictive value, the diagnostic performance of CCTA is limited by the relatively low specificity, especially in patients with heavily calcified lesions. The discrepancy between the degree of stenosis and ischemia is well established based on both invasive and noninvasive tests. The rapid evolution of computational flow dynamics has allowed the simulation of CCTA derived fractional flow reserve (FFR-CT), which improves specificity by combining anatomic and functional information regarding coronary atherosclerosis. FFR-CT has been extensively validated against invasively measured FFR as the reference standard. Due to recent technological advancements FFR-CT values can also be calculated locally, without offsite processing. Wall shear stress (WSS) and axial plaque stress (APS) are additional key hemodynamic elements of atherosclerotic plaque characteristics, which can also be measured using CCTA images. Current evidence suggests that WSS and APS are important hemodynamic features of adverse coronary plaques. CCTA based hemodynamic calculations could therefore improve prognostication and the management of patients with stable CAD.
\end{abstract}

\section{KEYWORDS}

computational fluid dynamic, computed tomography angiography derived fractional flow reserve, wall shear stress, axial plaque stress, coronary artery disease

\section{Introduction}

Coronary Computed Tomography Angiography (CCTA) is currently the most accurate noninvasive imaging modality that enables the detection and characterization of coronary artery disease (CAD) [1-3]. CCTA has high negative predictive value and high sensitivity to diagnose obstructive CAD. In addition to its high accuracy, it is also cost-effective and provides strong prognostic information, therefore, the National Institute for Health and Care Excellence (NICE) guideline in 2016 considered CCTA as the first line test for stable chest pain patients [4, 5]. Moreover, according to the recent, 2019 European Society of Cardiology Guideline, CCTA has a Class I recommendation in terms of the management and diagnosis of chronic coronary syndromes in patients in whom the presence of obstructive CAD cannot 
be ruled out based on clinical assessment alone [6]. Despite recent developments in scanner technology the specificity of CCTA is limited and it is well recognized that CCTA tends to overcall the degree of luminal narrowing especially in calcified lesions, leading to reduced diagnostic accuracy. This may result in the increased rates of unnecessary downstream testing and thus might become a growing problem as CCTA can be considered a first line test for stable angina patients with a large variety of pre-test likelihood of CAD [7]. The need to improve clinical decision making by addressing the limitations of CCTA has led to the development of CT-based hemodynamic simulations [8-11]. Due to recent technological advancements, non-invasive hemodynamic simulations using computational flow dynamics (CFD) have reshaped the diagnostic and treatment plans of patients with CAD. CCTA derived fractional flow reserve (FFR-CT) is a promising tool to detect lesion specific ischemia and identify patients for subsequent revascularization [12]. Currently, fractional flow reserve (FFR) is the gold standard assessment of hemodynamic significance for coronary stenosis as measured by invasive angiography [1315]. FFR represents the ratio of the mean coronary pressure distal to a coronary stenosis to the mean aortic pressure during maximal coronary blood flow induced by adenosine $[16,17]$. This hemodynamic parameter can be measured during invasive coronary angiography (ICA) and it is one of the essential tools to guide coronary revascularization [18, 19]. FFR-CT has been extensively validated against invasively measured FFR as a reference standard [8, 9, 20]. FFR$\mathrm{CT}$ is able to estimate the intracoronary pressure drop caused by an atherosclerotic plaque without inducing hyperemia, with a high diagnostic accuracy and good correlation to invasive assessment [21, 22]. The FFR-CT values can be simulated either off-site or using one of the more recently developed on-site calculation techniques $[8,9,20$, $23,24]$. Among several other hemodynamic forces wall shear stress (WSS) may be considered as an additional hemodynamic parameter that can influence the initiation and development of atherosclerotic plaques $[25,26]$. In terms of plaque vulnerability, axial plaque stress (APS) could be another important hemodynamic parameter that can be assessed using CCTA images and seem to influence plaque morphology and vulnerability [25]. Few clinical studies have already demonstrated the clinical relevance of these two hemodynamic indices [27-29].

Current review focuses on the role of FFR-CT, WSS, and APS using CT based hemodynamic simulations for the evaluation of ischemic heart disease $[1,4,30]$.

\section{Technical aspects and diagnostic accuracy of CT derived FFR}

Despite proven benefits of CCTA in terms of assessing patients with suspected CAD, traditional CCTA is limited to anatomical assessment of $\mathrm{CAD}$ without the ability to predict hemodynamically significant CAD [30-32]. At present, there are two methods for calculating FFR-CT values. Firstly, the off-site FFR-CT technique includes the three-dimensional (3D) modeling of the coronary tree as a whole with computation of FFR values throughout the entire coronary tree. This technique is available by the HeartFlow Inc. and it is approved for clinical use by the United States Food and Drug Administration [8, 9, 33]. The other method is the onsite technique which can be simulated using dedicated FFRCT workstations by clinicians. Despite the fact that these workstations are not commercially available yet several vendors developing software prototypes dedicated to CT based FFR simulations, including Siemens, Toshiba, and Philips [34-39].

Three main steps are needed in order to calculate FFR values based on rest CCTA images using off-site algorithms. The anatomical modeling of coronary arteries, physiological modeling of blood flow and the solution of the governing equations of blood flow. The 3D method is able to estimate coronary blood flow for every branch and side branch of the given heart's coronary arteries [40]. Computational fluid dynamics and image based modeling has led to the analyses of rest and hyperemic coronary flow and pressure from CCTA scans, with unchanged radiation dose and acquisition protocols, additional imaging or any changes in medications during the examination [40]. Figure 1 demonstrates a representative case of FRR-CT estimation for suspected CAD.

Off-site FFR-CT technique has been validated against invasively measured FFR as a reference standard in several studies such as DISCOVER-FLOW (Diagnosis of IschemiaCausing Stenoses Obtained Via Noninvasive Fractional Flow Reserve), DeFACTO (Determination of Fractional Flow Reserve by Anatomic Computed Tomographic AngiOgraphy) and NXT trials $[8,9,33]$. Similarly, to invasive FFR, FFR-CT value of $\leq 0.80$ is generally considered as positive (hemodynamically relevant $\mathrm{CAD}$ ), although some studies used a cut-off value of $\leq 0.70$ or $\leq 0.75$.

Compared to off-site FFR-CT, scientific literature lacks studies regarding the usefulness of on-site FFR-CT techniques and their advantages, hence it has not been used in clinical practice yet. The on-site FFR-CT software tool operates on a regular workstation with the use of semiautomated 3D coronary-artery modeling and one of the following three types of algorithms: the reduced-order CFDbased FFR calculations [34, 35] CFD-based FFR calculations with an artificial intelligence (AI) algorithm [36] or machine learning (ML)-based FFR-CT calculations [37-39]. In a retrospective study by Coenen et al. [34] 106 patients' conventional ICA data was used to calculate FFR using a local workstation. The aim was to validate an on-site algorithm for FFR computation from CCTA data against invasive FFR measurements. In case of healthy nonstenotic coronary arteries for the coronary microvasculature a reduced-order model was used [41]. In the regions with stenosis in order to model the physical flow, hybrid models were combined with the reduced-order model to simulate the coronary blood flow [42]. Two expert physicians performed the readings. The time for the segmentation varied between 0.5 and 2 


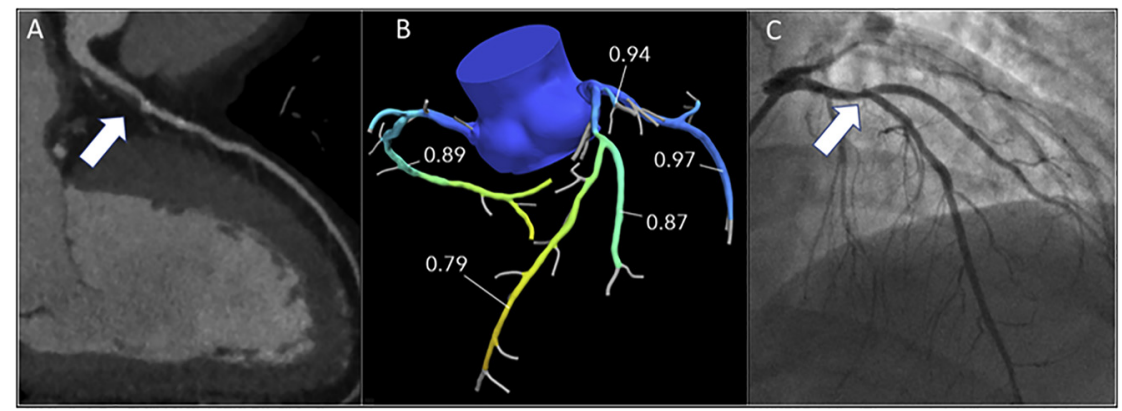

Fig. 1. Representative clinical case for the assessment of lesion specific ischemia using CT-FFR. A: Coronary CT angiography: the arrow is pointed at a high-risk plaque (HRP) in the proximal LAD causing an approximately $50-69 \%$ obstruction. B: FFR derived from coronary CT: FFR values were calculated by using the patient's coronary CT scan, the circle indicates to the HRP seen on picture A. C: Invasive coronary angiography: the arrow is pointed at the same obstruction that caused by a high risk plaque seen on picture A. Invasive FFR was 0.77 , thus the LAD lesion was stented

hours per patient and an additional 5-10 minutes for the FFR calculation. The overall correlation between FFR-CT and invasive FFR was moderate to good (Pearson correlation coefficient (Pearson R) $=0.59$ ) with a lower mean outcome for FFR-CT compared to that of invasive FFR. When compared to CCTA the discriminatory value of hemodynamically significant CAD improved by FFR-CT (Area Under the Curve (AUC): 0.64 versus $0.83 P<0.001$, respectively). Similar improvement was demonstrated in terms of specificity, from $37.6 \%$ (95\% CI: $28.5 \%, 47.4 \%)$ to 65.1\% (95\% CI: 55.4\%, 74.0\%) $(P<0.001)$ without an influence on sensitivity, which was $81.3 \%$ (95\% CI: $71.0 \%$, $89.1 \%)$ and $87.5 \%$ (95\% CI: $78.2 \%, 93.8 \%)$, respectively $(P=0.360)$. The diagnostic accuracy of FFR-CT was substantially higher than CCTA $(74.6 \%$ (95\% CI: $68.4 \%$, $80.8 \%$ ); $56.1 \%$ (95\% CI: $49.0 \%, 63.2 \%$ ). The use of FFR-CT therefore outperforms CCTA and correlates well with invasive FFR. It might also be performed in routine clinical setting as the FFR-CT simulation requires 35-40 minutes in total [34].

Donelly et al. [36] sought to evaluate the diagnostic performance of an AI algorithm based FFR-CT as compared with invasive FFR. Notably, the FFR-CT value is affected by inter-observer variations in terms of lumen segmentation. Fortyfour patients with 60 coronary atherosclerotic lesions' FFR values were compared between CCTA and ICA. The semi-automated coronary lumen segmentation for effective diameter stenosis and the on-site FFR-CT computational simulation was carried out by two expert readers. The automatic lumen segmentation was performed by a Comprehensive Cardiac Analysis software (IntelliSpace Portal Version 6.0, Philips Healthcare, Best, The Netherlands). On-site FFR-CT had substantially greater diagnostic performance than effective diameter stenosisbased evaluation (AUC: 0.89 versus 0.74 , respectively, $P<$ $0.001)$. Intra and inter- reader reliability showed great reproducibility with intra-class correlation coefficients of 0.95 and 0.90 , respectively. This novel on-site FFR-CT algorithm allows for rapid measurements of CT based FFR values. The time needed to segment and manually adjust the lumen was between 3 and 25 minutes with an additional 5 seconds to the simulation of FFR-CT. ML-based FFR computation applies a combination of pattern recognition and computational learning to derive $\operatorname{FFR}[36,38]$.

An alternative to CFD-based modeling, a near real-time, ML model for FFR computation was first introduced by Itu et al. [43] This trained model created a database with 12,000 coronary anatomies that was synthetically generated, which was the key element of this study. Using the CFD model the ML model was able to learn the relationship between the FFR value and anatomic features of the coronaries. The method was validated against CFD based FFR on synthetic and patient-specific anatomical models. As of the latter 87 patient-specific anatomical models were included and 125 lesions were measured for invasive FFR in this patient population. The computation time on an average for calculating ML-FFR was $2.4 \pm 0.44$ s. The diagnostic performance of ML-FFR and CFD-FFR were also evaluated taking the invasive FFR as a gold standard. The sensitivity, specificity and accuracy of ML based FFR were 81.6, 83.9, $83.2 \%$ respectively. A close correlation was shown between ML based FFR and the invasive FFR technique which demonstrate the statistical comparability of the two methods. The same algorithm and strategy were used within the framework of The Machine Learning Based CT Angiography Derived FFR: A Multi-Center Registry (MACHINE) consortium included 351 patients with 525 vessels for analysis. There was an excellent correlation between MLbased and CFD based FFR (Pearson $r=0.997$ ) while there was a moderate correlation between ML-based FFR and invasive FFR (Pearson $r=0.62$ ). On a per-vessel level, in case of more than $50 \%$ stenosis ML-based FFR-CT improved specificity, accuracy and positive predictive value, whereas in case of more than $70 \%$ of stenosis sensitivity, accuracy and negative predictive value improved with the application of ML-based FFR-CT as compared with CCTA. On a per patient level the positive predictive value (89\%) and the overall diagnostic accuracy (85\%) improved by adding ML-based FFR-CT $[38,43]$. According to these promising study results ML-based algorithms might play a more significant role in the future of CCTA with rapid assessment of hemodynamically significant CAD. 


\section{The advantages of FFR based CT in clinical practice}

Recently, functional information based on CCTA scans became available in clinical decision making [44]. Several studies examined the clinical usefulness of FFR-CT with the aim to determine whether FFR-CT can predict percutaneous coronary intervention (PCI) or adverse clinical outcomes. (Table 1). A sub-study of The Prospective Multicentre Imaging Study for Evaluation of Chest Pain (PROMISE) trial sought to assess whether it enhances the efficiency of the referral to ICA after CCTA [45]. Among patients in whom ICA was also performed after CCTA, their images were sent to an FFR-CT core lab to derive FFR values in a blinded fashion. The main finding of the study was that FFR-CT may ameliorate the efficiency of ICA referrals as 50 out of 181 patients would not require an invasive test [45]. If FFRCT would theoretically have been used in the CCTA arm the rate of non-obstructive disease at the time of catheterization would have been reduced from 28 to $12 \%$ using FFR-CT as a gatekeeper.

In another study within the Analysis of Coronary Blood Flow Using CT Angiography: Next Steps (NXT) trial called RIPCORD (Does Routine Pressure Wire Assessment Influence Management Strategy at Coronary Angiography for Diagnosis of Chest Pain?) study the clinical significance of FFR-CT was tested compared to CCTA alone strategy [46]. Three interventional cardiologists evaluated the CCTA data of 200 patients and by consensus developed a management plan that included any of the following: optimal medical therapy, percutaneous coronary intervention, coronary artery bypass graft surgery, or more information was required. Subsequently, FFR-CT data for each vessel were revealed and a second plan was made based on the FFR values. The availability of FFR data led to an overall change in the decision for treatment in 72 cases $(36 \%)$ of the study population compared to CCTA strategy alone. This study demonstrated a proof of concept which indicates that the availability of FFR-CT has an essential role in identifying significant $\mathrm{CAD}$, hence on the management of patients with stable chest pain [46].

Regarding the clinical utility of FFR-CT, the Prospective LongitudinAl Trial of FFRct: Outcome and Resource IMpacts (PLATFORM) trial was one of the firsts to demonstrate that in patients with an indication for ICA $(n=380)$, applying the results of FFR-CT $(n=193)$ significantly decreased the number of required ICAs [47]. This comprehensive prospective study sought to determine the one year clinical, quality of life and economic outcomes of FFR-CT instead of applying usual care management. Despite the fact that the PLATFORM trial consisted of a relatively small sample size the results are promising. The use of CCTA with FFR-CT was related to significantly lower rates of ICA without obstructive CAD [risk difference of - 6.5 (95\% confidence interval (CI): -14.4 to $1.4 ; P=0.95)][25,43]$. As for the economic outcomes, the mean 1-year per-patient cost of medical care was significantly lower in the FFR-CT guided arm when compared to the usual care strategy $(\$ 8,127$ versus $\$ 12,145 ; P<0.0001)$. However, the functional status and quality of life improvement during the one-year follow-up were similar in all examined groups [47].

The first large multicenter prospective study using CCTA and FFR-CT diagnostic strategies was The Assessing Diagnostic Value of Non-invasive FFR-CT in Coronary Care (ADVANCE) registry [44]. It was designed to evaluate the real-world utility and the impact of FFR-CT in various healthcare settings, geographical areas and patient populations. Five thousand eightythree patients were enrolled from Europe, Japan, and North America from 2015 to 2017, and were diagnosed with CAD on CCTA. CCTA scans, if the stenosis degree ranged between 30 and 90\%, were directed to HeartFlow for off-site FFR analysis. A value of $\leq 0.80$ was considered positive [48]. A blinded core laboratory established a management strategy for patients based on rest CCTA alone. Subsequently, FFR-CT results were revealed which re-determined the treatment strategy. The follow-up results of 90 days demonstrated that $66.9 \%$ of patients had changes in management plans when incorporating FFR-CT. In patients with an FFR-CT value of $\leq 0.80$, the rate of anatomically defined non-obstructive $\mathrm{CAD}$ at ICA was substantially lower than with FFR-CT $>0.80,14.4 \%$ and $43.8 \%$ respectively $(P<0.001)$. Moreover, FFR-CT results could predict the likeliness of ICA and PCI (the percentage of ICA in terms of FFR-CT values: FFR-CT $\leq 0.70$ : $73.8 \%$ versus FFR-CT $>0.80: 20.5 \%$, the percentage of subsequent revascularization in terms of FFR-CT values: FFRCT $\leq 0.70: 72.5 \%$ versus FFR-CT $>0.80: 20.4 \% P<0.001$ ). In addition, as an advantage in favor of FFR-CT within 90 days no death or MI occurred in any patients whose FFR-CT value was $>0.80$. However, based on the 1 year follow-up results out of the total 55 MACE occurrence, 43 had a positive and 12 had a negative FFR-CT results $(P=0.06)$. Similarly, the number of cardiovascular death or MI was significantly higher in positive FFR-CT patients (25 [0.80\%] versus $3[0.20 \%] ; P=0.01)$. Based on these results it can be concluded that the usage of FFR-CT improves patients' outcome [44, 49]. This previously mentioned concept was also emphasized in the EMERALD (Exploring the Mechanism of Plaque Rupture in Acute Coronary Syndrome Using Coronary CT Angiography and Computational Fluid Dynamic) study [29].

Importantly, another study evaluated the role of noninvasive FFR in selecting patients with multivessel disease for revascularization. In the SYNTAX III Revolution study (A Randomized Study Investigating the Use of CT Scan and Angiography of the Heart to Help the Doctors Decide Which Method is the Best to Improve Blood Supply to the Heart in Patients With Complex Coronary Artery Disease), FFR-CT was examined for its role in treatment decision changes and planning in terms of coronary artery bypass graft versus PCI [50]. A total of 1,030 lesions were analyzed and FFR-CT modified the treatment decision and the selection of vessels for revascularization in 7 and $16 \%$ of the patients respectively. FFR-CT as a non-invasive tool changed 
Table 1. Clinical value of CT derived FFR

\begin{tabular}{|c|c|c|c|c|c|c|}
\hline Year, Author & Patient number & Study & Study design & Examinations & Objectives & Outcomes \\
\hline 2014, Nørgaard et al. & 251 & NXT & Prospective & CCTA, FFR-CT & $\begin{array}{l}\text { Diagnostic accuracy, } \\
\text { reference iFFR }\end{array}$ & $\begin{array}{c}\text { The diagnostic accuracy of FFR-CT is } \\
\text { higher than CCTA for ischemia } \\
\text { detection }\end{array}$ \\
\hline 2014, Curzen et al. & 200 & RIPCORD & Prospective & CCTA, FFR-CT & Patient management & $\begin{array}{l}\text { The use of FFR-CT data has led to a } \\
\text { change in patient management in } 36 \% \\
\text { of the cases }\end{array}$ \\
\hline 2016, Douglas et al. & 584 & PLATFORM & $\begin{array}{l}\text { Sub-study, } \\
\text { prospective }\end{array}$ & CCTA, ICA, FFR-CT & Patient management & $\begin{array}{c}\text { FFR-CT: feasible and safe alternative to } \\
\text { ICA, significantly lower rate of ICA } \\
\text { showing non-obstructive CAD }\end{array}$ \\
\hline 2017, Lu et al. & 550 & PROMISE & $\begin{array}{c}\text { Retrospective, } \\
\text { observational cohort }\end{array}$ & CCTA, ICA, FFR-CT & Patient management & $\begin{array}{c}\text { FFR-CT of } \leq 0.8 \text { was a better predictor } \\
\text { of revascularization or MACE than } \\
\text { severe stenosis on CCTA }\end{array}$ \\
\hline 2019, Andreini et al. & 223 & SYNTAX III & $\begin{array}{l}\text { Observational, } \\
\text { cross sectional }\end{array}$ & CCTA, FFR-CT & Patient management & $\begin{array}{l}\text { Implementing FFR-CT in the SYNTAX } \\
\text { score changed treatment decision in } 7 \% \\
\text { of the patients and modified selection of } \\
\text { vessels for revascularization in } 12 \%\end{array}$ \\
\hline 2020, Patel et al. & 5083 & ADVANCE & Prospective & CCTA, FFR-CT & $\begin{array}{l}\text { Patient management, } \\
\text { prognostic value }\end{array}$ & $\begin{array}{l}\text { Negative FFR-CT values are associated } \\
\text { with lower MACE and significantly } \\
\text { lower cardiovascular death or MI } \\
\text { compared to patients with positive FFR- } \\
\text { CT values }\end{array}$ \\
\hline
\end{tabular}

CAD: Coronary Artery Disease, CCTA: Coronary Computed Tomography Angiography, FFR-CT: CCTA Derived Fractional Flow Reserve, ICA: Invasive Coronary Angiography, iFFR: Invasive Fractional Flow Reserve, MACE: Major Adverse Cardiac Events, MI: Myocardial Infarction. 
the heart team's treatment decision-making and procedural planning in one in five patients with 3-vessel CAD [50].

\section{Advanced plaque characterization using novel hemodynamic parameters}

FFR represents the cumulative hemodynamic effect of an epicardial lesion on the myocardium [51], however regional plaque hemodynamic factors also contribute to subsequent acute coronary syndromes $[52,53]$. In the following WSS and APS will be discussed for possible clinical use (Table 2). Figure 2 summarizes the anatomical and functional characteristics of stable and vulnerable plaques.

\section{Wall shear stress}

A coronary lesion that is considered hemodynamically significant can lead to a spectrum of changes in fluid dynamic forces upstream from the lesion as well as within and distal to the lesion [53]. An important hemodynamic factor is the WSS which is a tangential force per unit area acting on and parallel to the luminal surface of the endothelium $[25,53]$. If it is physiological, WSS has been related to atheroprotective signaling pathways whereas low WSS may cause inflammation and activation of proatherogenic pathways while in case of high WSS with the activation of matrix metalloproteinase might lead to plaque vulnerability $[54,55]$. In addition, regression of fibrous tissue and fibrofatty tissue, the development of increased plaque strain, expansive remodeling and progression of the necrotic core and calcium are also associated with high WSS values [25, 56]. Moreover, thin-cap fibroatheromas co-localize within the regions of high WSS in the proximal region segment [57]. Parallel with these findings, several studies observed that plaque rupture often develops in the proximal region of the stenosis, which leads to the conclusion that local hemodynamic forces play an important role in the development of acute coronary syndromes [58, 59]. Furthermore, it is hypothesized that WSS recruit inflammatory cells leading to vasoconstriction and change in the morphology of endothelial cells. WSS also has a significant role as a substrate that might contribute to plaque rupture or erosion [25]. Plaque erosion site predominantly display fibrotic, smooth muscle cell and proteoglycan components [60]. Plaque erosion is hypothesized to occur when an extremely high magnitude of shear is present in a stenotic flow. High WSS could lead to the detachment of endothelium which creates a thrombogenic surface in connection with the blood flow [61]. Evaluating WSS in human coronary arteries with image-based modeling on invasive data have already been introduced [25, 62]. However, using non-invasive data to assess WSS is less frequent [63-65]. In a post-hoc analysis of the DeFacto study including 100 patients, the association of WSS to atherosclerotic plaque characteristics as assessed by CCTA was evaluated using invasive FFR as a reference standard [27]. Notably, high WSS was associated with increased stenosis severity $(55 \pm 13.4 \%)$ and the presence of positive remodeling and low attenuation plaque $(P=0.006$ and $P=$ 0.002 , respectively) which are the components of high-risk plaque features (Fig. 3). Sixty (36.8\%) lesions led to significant ischemia. FFR and WSS values were inversely related as when WSS values were high the FFR values were significantly lower (the value of FFR in the high WSS group: $0.79 \pm$ 0.13 versus the value of FFR in the low WSS group: $0.86 \pm$ $0.13, P=0.011$ ) [27].

In the FAME II (Fractional Flow Reserve Versus Angiography for Multivessel Evaluation II) trial a post-hoc analysis was carried out to investigate the prognostic value of WSS that was measured in the proximal segments of the lesions in order to predict myocardial infarction (MI) in patients with stable CAD and FFR positive lesions [28]. In the post-hoc analysis 441 patients received medical therapy only. Within 3 years 34 patients had myocardial infarction. Twentynine patients who had appropriate CCTA for 3D reconstruction were propensity matched to a control group who did not have MI $(n=29)$. FFR and WSS values were calculated. In conclusion, the median values of WSS prox WSS $_{\text {total_lesions }}$ were substantially higher among the MI group in contrast with the non-MI control patients $(P<0.05$ for all). Comparably, baseline FFR values were lower in those patients who had vessel related MI compared with the control group $(P=0.012)$. For the model that predicts vessel-related MI, adding proximal WSS to FFR substantially improved the predictive value $(P=0.005)$. This study demonstrated that WSS $_{\text {prox }}$ had the highest prognostic value in the prediction of MI and has incremental prognostic value over FFR at 3 years [28]. In the diagnosis and treatment of CAD the evaluation of both WSS and FFR are essential and large prospective studies are needed to establish preventive strategies based on WSS and FFR in order to prevent plaque progression and adverse events. The future application of image-based modeling derived from CT data holds great promise for understanding the relationship between WSS and CAD development.

\section{Axial plaque stress}

Several other plaque and vasculature related biomechanical parameters might be essential in the prediction of myocardial infarction. Axial plaque stress is also among the key hemodynamic indices in terms of plaque vulnerability [25, 29].

Choi et al. [25] were among the firsts who proposed a hemodynamic index, called APS, to assess the future risk for plaque rupture and to determine treatment strategies for patients with CAD. APS is a fluid stress that communicates to the surface of the plaque and can be seen as the key element for the force imbalance throughout the lesion. Eightyone patients were enrolled in the study with 114 nonostial lesions. Eightyone lesions showed net anterograde axial plaque force with substantially higher values in the upstream segment, while 33 lesions showed net retrograde axial plaque force with significantly higher downstream axial plaque force. The magnitude of APS was greater than that of the WSS. A linear relationship was observed in the upstream 
Table 2. CCTA based hemodynamic assessment of WSS and APS in recent studies

\begin{tabular}{|c|c|c|c|c|c|c|}
\hline Year, Author & Patient number & Study & Study design & WSS/APS & Objectives & Outcomes \\
\hline 2007, Frauenfelder et al. & 5 & - & Retrospective, feasibility & WSS & $\begin{array}{c}\text { Non-invasive assessment of } \\
\text { hemodynamic parameters including } \\
\text { WSS by CCTA using CFD }\end{array}$ & $\begin{array}{l}\text { The simulation of pulsatile blood flow is } \\
\text { feasible in-vivo in coronary arteries of } \\
\text { patients with geometric data obtained } \\
\text { from multi-detector row CT }\end{array}$ \\
\hline 2015, Choi at al. & 81 & - & Retrospective & APS & Effects of APS on lesion geometry & $\begin{array}{l}\text { APS presented a lesion geometry- } \\
\text { dependent distribution contrary to non- } \\
\text { invasive FFR and WSS values }\end{array}$ \\
\hline 2016, Park et al. & 80 & - & Retrospective & WSS & $\begin{array}{l}\text { Association of shear-related forces and } \\
\text { atherosclerotic plaques }\end{array}$ & $\begin{array}{l}\text { High WSS might indicate high-risk } \\
\text { plaque development }\end{array}$ \\
\hline 2016, Donghee et al. & 100 & DeFacto & Post-hoc analysis & WSS & Relationship of FFR, WSS and APC & $\begin{array}{l}\text { High WSS is associated with APCs } \\
\text { independent of stenosis severity. WSS } \\
\text { had no incremental value beyond } \\
\text { stenosis severity and APC for detecting } \\
\text { lesions specific ischemia }\end{array}$ \\
\hline 2018, Kumar et al. & 441 & FAME II & Post-hoc analysis & WSS & $\begin{array}{l}\text { Prognostic value of WSS to predict MI } \\
\text { in patients with stable CAD and } \\
\text { hemodynamically significant lesions }\end{array}$ & $\begin{array}{l}\text { Higher } \text { WSS }_{\text {prox }} \text { of atherosclerotic } \\
\text { lesions is predictive of MI and has } \\
\text { incremental prognostic value over FFR }\end{array}$ \\
\hline 2018, Lee et al. & 72 & EMERALD I & Retrospective & WSS, APS & $\begin{array}{c}\text { Non-invasive hemodynamic assessment } \\
\text { in the identification of high-risk plaques } \\
\text { that caused subsequent acute coronary } \\
\text { syndrome }\end{array}$ & $\begin{array}{c}\text { Culprit lesions showed lower FFR CT } \\
\text { and higher } \Delta \text { FFR-CT, WSS, and APS } \\
\text { than non-culprit lesions }\end{array}$ \\
\hline
\end{tabular}

APC: Adverse Plaque Characteristics, APS: Axial Plaque Stress, CAD: Coronary Artery Disease, CCTA: Coronary Computed Tomography Angiography, CFD: Computational Flow Dynamics, FFR: Fractional Flow Reserve MI: Myocardial Infarction, WSS: Wall Shear Stress. 


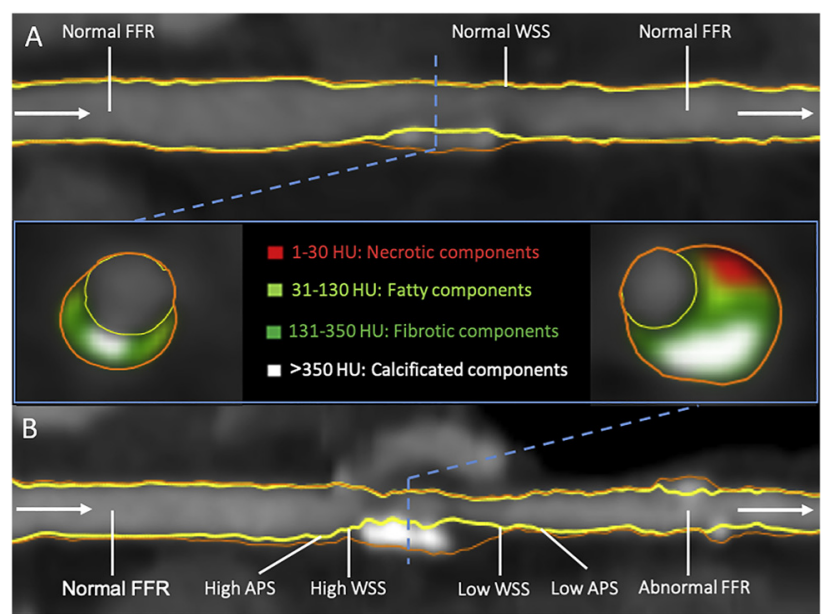

Fig. 2. The anatomical and functional characteristics of stable and vulnerable plaques. Panel A demonstrates a stable lesion with fibrofatty components and spotty calcification. The plaque causes a minimal luminal obstruction and no ischemia can be detected after the lesion. WSS is in the physiological range which leads to an undisturbed blood flow with normal CT-FFR values. Panel B presents a vulnerable plaque with necrotic, fibrofatty and calcified components. The lesion leads to moderate luminal narrowing and myocardial ischemia. CT-FFR value was 0.78 . FFR: fractional flow reserve, WSS: wall shear stress, APS: axial plaque stress, HU: Hounsfield Unit

segment between APS and pressure gradient as well as between lesion severity and APS, while downstream APS showed a concave shape. The latter indicates that a risk for a downstream rupture is lower in severe stenosis due to decreased downstream pressure. There was a negative correlation between lesion length and APS. Importantly, APS presented a lesion geometry-dependent distribution contrary to non-invasive FFR and WSS values [25]. The results indicate more precise risk stratification in terms of CAD.

This previously mentioned concept was also emphasized in the EMERALD study [29]. The aim of the study was to assess the benefits of non-invasive hemodynamic indices in the identification of high-risk plaques that led to acute coronary syndrome. In this retrospective study 11 centers in 5 countries collected those patients' CCTAs that were acquired between 1 month and 2 years before the acute coronary event developed. In a case-control design, 72 patients with 66 culprit and 150 nonculprit lesions were analyzed. As part of the study APS, $\mathrm{FFR}_{\mathrm{CT}}, \Delta \mathrm{FFR}_{\mathrm{CT}}$, and WSS values were assessed. Regarding culprit lesions APS along with the previously mentioned hemodynamic factors showed lower values that of the hemodynamic values of nonculprit lesions (all $P$ values $<0.01$ ). Whereas, inversely in terms of adverse plaque characteristic culprit lesions showed a higher frequency of positive remodeling, low-attenuation plaque, spotty calcification and napkin-ring sign than nonculprit lesions (all $P$ values $<0.01$ ). The results indicated that the additional evaluation of non-invasive hemodynamic factors improved the identification of high-risk plaques that led to acute coronary syndrome in a 2-year period [29].

Several imaging based studies described vulnerable plaque features in order to better understand the risks of developing acute coronary syndrome. Although, these characteristics does not provide any information about mechanical forces. Therefore, adding information about these forces, risk stratification and treatment strategy may be further improved.

\section{Limitations of the novel hemodynamic parameters}

Despite the positive attributes (high specificity) of FFR-CT which are promising regarding its future application in a clinical setting, this method also has some limitations we need to acknowledge. FFR-CT analysis requires excellent image quality in order to simulate FFR values as it can only be implemented if there is a motion-free cardiac phase of the coronary tree and the myocardium $[8,44,66]$. Calcification or misalignment artifacts could also limit the quality of the coronary tree models [67]. In addition, the CCTA scans of patients with CABG, stents, prior myocardial infarction, microvascular dysfunction might not be analyzed [68-70]. In the NXT, DeFACTO, DISCOVER-FLOW trials the proportion of rejected CCTA scans were between 11 and 13\%, whereas in the substudy of the PROMISE trial this percentage was 33\%, although this study was not designed for FFR-CT simulations $[8,71]$. Another limitation is its relatively large wideness of the 'grey zone' range (0.7-0.9) compared to invasive FFR (0.750.80 ). This might create an uncertainty regarding clinical decision making [72]. Moreover, the diagnostic accuracy of FFRCT is decreased by the abnormal FFR-CT values that can be seen at the distal segments of the coronary tree due to the declining pressure along the narrowing vessel [73-75].

CT based WSS has similar limitations as FFR based CT simulation as its value is highly dependent on image quality.

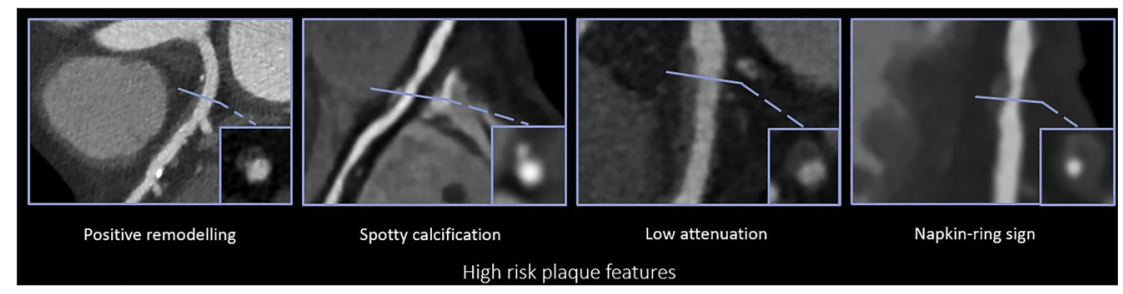

Fig. 3. High-risk plaque features detected by coronary CT angiography. Coronary CTA allows for the detection of high-risk plaque features that were linked to adverse cardiac events 
Moreover, Molony et al. demonstrated that in order to calculate WSS side branches of the coronaries should be included, otherwise it could alter blood flow estimation and WSS values [76]. Hemodynamic parameters as WSS and APS are both dynamic indices that are affected by several factors such as other local forces at the lesion site [27] but the latest technological advancements are not able to consider all potential contributory factors. Large prospective studies and more advanced technologies are warranted to have a better understanding of hemodynamic parameters that are essential in the development of CAD. Furthermore, outcome studies are needed to verify the assessment of WSS and APS in clinical practice.

\section{Conclusion}

CFD led to the opening of a new chapter to CCTA due to its constantly improving ability to provide information about anatomic, functional and hemodynamic characteristics of plaques. Off-site FFR calculation is able to give fast and effective assessment of the coronary arteries, and aid clinical decision making and might have a greater role in the future. However, more studies are warranted regarding on-site FFR assessments. Integrating adverse plaque characteristic, hemodynamic factors such as FFR, WSS and APS, and anatomical severity to improve the identification of high-risk plaques will help identify groups at-risk and help prevention of acute coronary event.

Funding sources: The project was supported by the KH-17 Programme of the National Research, Development and Innovation Office of the Ministry of Innovation and Technology in Hungary (NKFIH). The project was supported by the "NTP-NFTÖ" (Nemzeti Tehetség Program, Nemzet Fiatal Tehetségeiért Ösztöndíj) program of the Ministry of Human Capacities in Hungary (EMMI). Bálint Szilveszter was supported by the ÚNKP 2020/21 Grant. The research was financed by the Thematic Excellence Programme (Tématerületi Kiválósági Program, 2020-4.1.1.-TKP2020) of the Ministry for Innovation and Technology in Hungary, within the framework of the Therapeutic Development and Bioimaging programmes of the Semmelweis University.

Authors' contribution: All authors reviewed the final version of the manuscript and agreed to submit it to IMAGING for publication.

Conflict of interest: The authors have no conflict of interest to disclose.

\section{REFERENCES}

[1] Budoff MJ, Dowe D, Jollis JG, Gitter M, Sutherland J, Halamert E, et al.: Diagnostic performance of 64-multidetector row coronary computed tomographic angiography for evaluation of coronary artery stenosis in individuals without known coronary artery disease: results from the prospective multicenter ACCURACY (Assessment by Coronary Computed Tomographic Angiography of Individuals Undergoing Invasive Coronary Angiography) trial. J Am Coll Cardiol 2008; 52(21): 1724.

[2] Meijboom WB, Meijs MF, Schuijf JD, Cramer MJ, Mollet NR, van Mieghem CA, et al.: Diagnostic accuracy of 64-slice computed tomography coronary angiography: a prospective, multicenter, multivendor study. J Am Coll Cardiol 2008; 52(25): 2135.

[3] Paech DC, Weston AR: A systematic review of the clinical effectiveness of 64-slice or higher computed tomography angiography as an alternative to invasive coronary angiography in the investigation of suspected coronary artery disease. BMC Cardiovasc Disord 2011; 11: 32.

[4] Miller JM, Rochitte CE, Dewey M, Arbab-Zadeh A, Niinuma H, Gottlieb I, et al.: Diagnostic performance of coronary angiography by 64-row CT. N Engl J Med 2008; 359(22): 2324.

[5] Padley SPG, Roditi G, Nicol ED: Chest pain of recent onset: assessment and diagnosis (CG95). A step change in the requirement for cardiovascular CT. Clin Radiol 2017; 72(9): 751.

[6] Konstantinides SV, Meyer G, Becattini C, Bueno H, Geersing G-J, Harjola V-P, et al.: ESC Guidelines for the diagnosis and management of acute pulmonary embolism developed in collaboration with the European Respiratory Society (ERS): the task force for the diagnosis and management of acute pulmonary embolism of the European Society of Cardiology (ESC). Eur Heart J 2019; 41(4): 543.

[7] Yan RT, Miller JM, Rochitte CE, Dewey M, Niinuma H, Clouse ME, et al.: Predictors of inaccurate coronary arterial stenosis assessment by CT angiography. JACC Cardiovasc Imaging 2013; 6(9): 963.

[8] Nørgaard BL, Leipsic J, Gaur S, Seneviratne S, Ko BS, Ito H, et al.: Diagnostic performance of noninvasive fractional flow reserve derived from coronary computed tomography angiography in suspected coronary artery disease: the NXT trial (Analysis of Coronary Blood Flow Using CT Angiography: Next Steps). J Am Coll Cardiol 2014; 63(12): 1145.

[9] Koo BK, Erglis A, Doh JH, Daniels DV, Jegere S, Kim HS, et al.: Diagnosis of ischemia-causing coronary stenoses by noninvasive fractional flow reserve computed from coronary computed tomographic angiograms. Results from the prospective multicenter DISCOVER-FLOW (Diagnosis of Ischemia-Causing Stenoses Obtained Via Noninvasive Fractional Flow Reserve) study. J Am Coll Cardiol 2011; 58(19): 1989.

[10] Min JK, Leipsic J, Pencina MJ, Berman DS, Koo B-K, van Mieghem C, et al.: Diagnostic accuracy of fractional flow reserve from anatomic CT angiography. JAMA 2012; 308(12): 1237.

[11] Nørgaard BL, Hjort J, Gaur S, Hansson N, Bøtker HE, Leipsic J, et al.: Clinical use of coronary CTA-derived FFR for decisionmaking in stable CAD. JACC Cardiovasc Imaging 2017; 10(5): 541.

[12] Zarins CK, Taylor CA, Min JK: Computed Fractional Flow Reserve (FFTCT) derived from coronary CT angiography. J Cardiovasc Transl Res 2013; 6(5): 708.

[13] Balanescu S: Fractional flow reserve assessment of coronary artery stenosis. Eur Cardiol 2016; 11(2): 77.

[14] Mehta SR, Cannon CP, Fox KA, Wallentin L, Boden WE, Spacek $\mathrm{R}$, et al.: Routine vs selective invasive strategies in patients with acute coronary syndromes: a collaborative meta-analysis of randomized trials. JAMA 2005; 293(23): 2908. 
[15] Schampaert E, Kumar G, Achenbach S, Galli S, Tanaka N, Teraphongphom T, et al.: A global registry of fractional flow reserve (FFR)-guided management during routine care: study design, baseline characteristics and outcomes of invasive management. Catheteriz Cardiovasc Interven. $\mathrm{n} / \mathrm{a}(\mathrm{n} / \mathrm{a})$.

[16] Pijls NH, van Son JA, Kirkeeide RL, De Bruyne B, Gould KL: Experimental basis of determining maximum coronary, myocardial, and collateral blood flow by pressure measurements for assessing functional stenosis severity before and after percutaneous transluminal coronary angioplasty. Circulation. 1993; 87(4): 1354.

[17] Pijls NH, Van Gelder B, Van der Voort P, Peels K, Bracke FA, Bonnier HJ, et al.: Fractional flow reserve. A useful index to evaluate the influence of an epicardial coronary stenosis on myocardial blood flow. Circulation 1995; 92(11): 3183.

[18] Tonino PA, De Bruyne B, Pijls NH, Siebert U, Ikeno F, van't Veer $\mathrm{M}$, et al.: Fractional flow reserve versus angiography for guiding percutaneous coronary intervention. N Engl J Med 2009; 360(3): 213.

[19] De Bruyne B, Pijls NH, Bartunek J, Kulecki K, Bech JW, De Winter $\mathrm{H}$, et al.: Fractional flow reserve in patients with prior myocardial infarction. Circulation 2001; 104(2): 157.

[20] Nakazato R, Park HB, Berman DS, Gransar H, Koo BK, Erglis A, et al.: Noninvasive fractional flow reserve derived from computed tomography angiography for coronary lesions of intermediate stenosis severity: results from the DeFACTO study. Circ Cardiovasc Imaging 2013; 6(6): 881.

[21] Pijls NH, De Bruyne B, Peels K, Van Der Voort PH, Bonnier HJ, Bartunek JKJJ, et al.: Measurement of fractional flow reserve to assess the functional severity of coronary-artery stenoses. N Engl J Med 1996; 334(26): 1703.

[22] Davies JE, Sen S, Dehbi H-M, Al-Lamee R, Petraco R, Nijjer SS, et al.: Use of the instantaneous wave-free ratio or fractional flow reserve in PCI. New England J Med 2017; 376(19): 1824.

[23] Nozue T, Fukui K, Takamura T, Sozu T, Hibi K, Kishi S, et al.: Effects of alogliptin on fractional flow reserve evaluated by coronary computed tomography angiography in patients with type 2 diabetes: Rationale and design of the TRACT study. J Cardiol 2017; 69(3): 518.

[24] Yoshikawa Y, Nakamoto M, Nakamura M, Hoshi T, Yamamoto E, Imai S, et al.: On-site evaluation of CT-based fractional flow reserve using simple boundary conditions for computational fluid dynamics. Int J Cardiovasc Imaging 2020; 36(2): 337.

[25] Choi G, Lee JM, Kim HJ, Park JB, Sankaran S, Otake H, et al.: Coronary artery axial plaque stress and its relationship with lesion geometry: application of computational fluid dynamics to coronary CT angiography. JACC Cardiovasc Imaging 2015; 8(10): 1156.

[26] Samady H, Eshtehardi P, McDaniel MC, Suo J, Dhawan SS, Maynard C, et al.: Coronary artery wall shear stress is associated with progression and transformation of atherosclerotic plaque and arterial remodeling in patients with coronary artery disease. Circulation 2011; 124(7): 779.

[27] Han D, Starikov A, B ÓH, Gransar H, Kolli KK, Lee JH, et al.: Relationship between endothelial wall shear stress and high-risk atherosclerotic plaque characteristics for identification of coronary lesions that cause ischemia: a direct comparison with fractional flow reserve. J Am Heart Assoc 2016; 5(12).

[28] Kumar A, Thompson EW, Lefieux A, Molony DS, Davis EL, Chand $\mathrm{N}$, et al.: High coronary shear stress in patients with coronary artery disease predicts myocardial infarction. J Am Coll Cardiol 2018; 72(16): 1926.

[29] Lee JM, Choi G, Koo BK, Hwang D, Park J, Zhang J, et al.: Identification of high-risk plaques destined to cause acute coronary syndrome using coronary computed tomographic angiography and computational fluid dynamics. JACC Cardiovasc Imaging 2019; 12(6): 1032.

[30] Meijboom WB, Van Mieghem CA, van Pelt N, Weustink A, Pugliese F, Mollet NR, et al.: Comprehensive assessment of coronary artery stenoses: computed tomography coronary angiography versus conventional coronary angiography and correlation with fractional flow reserve in patients with stable angina. J Am Coll Cardiol 2008; 52(8): 636.

[31] Budoff MJ, Nakazato R, Mancini GB, Gransar H, Leipsic J, Berman DS, et al.: CT angiography for the prediction of hemodynamic significance in intermediate and severe lesions: head-tohead comparison with quantitative coronary angiography using fractional flow reserve as the reference standard. JACC Cardiovasc Imaging 2016; 9(5): 559.

[32] Leipsic J, Weir-McCall J, Blanke P: FFRCT for complex coronary artery disease treatment planning: new opportunities. Interv Cardiol 2018; 13(3): 126.

[33] Min JK, Berman DS, Budoff MJ, Jaffer FA, Leipsic J, Leon MB, et al.: Rationale and design of the DeFACTO (determination of fractional flow reserve by anatomic computed tomographic angiography) study. J Cardiovasc Comput Tomogr 2011; 5(5): 301.

[34] Coenen A, Lubbers MM, Kurata A, Kono A, Dedic A, Chelu RG, et al: Fractional flow reserve computed from noninvasive CT angiography data: diagnostic performance of an on-site clinicianoperated computational fluid dynamics algorithm. Radiology 2015; 274(3): 674.

[35] Fujimoto S, Kawasaki T, Kumamaru KK, Kawaguchi Y, Dohi T, Okonogi T, et al.: Diagnostic performance of on-site computed CTfractional flow reserve based on fluid structure interactions: comparison with invasive fractional flow reserve and instantaneous wave-free ratio. Eur Heart J Cardiovasc Imaging 2019; 20(3): 343.

[36] Donnelly PM, Kolossvary M, Karady J, Ball PA, Kelly S, Fitzsimons D, et al.: Experience with an on-site coronary computed tomography-derived fractional flow reserve algorithm for the assessment of intermediate coronary stenoses. Am J Cardiol 2018; 121(1): 9.

[37] Tesche C, Vliegenthart R, Duguay TM, De Cecco CN, Albrecht $\mathrm{MH}$, De Santis D, et al.: Coronary computed tomographic angiography-derived fractional flow reserve for therapeutic decision making. Am J Cardiol 2017; 120(12): 2121.

[38] Coenen A, Kim YH, Kruk M, Tesche C, De Geer J, Kurata A, et al.: Diagnostic accuracy of a machine-learning approach to coronary computed tomographic angiography-based fractional flow reserve: result from the MACHINE consortium. Circ Cardiovasc Imaging 2018; 11(6): e007217.

[39] Joshi AA, Lerman JB, Dey AK, Sajja AP, Belur AD, Elnabawi YA, et al.: Association between aortic vascular inflammation and coronary artery plaque characteristics in psoriasis. JAMA Cardiol 2018; 3(10): 949.

[40] Taylor CA, Fonte TA, Min JK: Computational fluid dynamics applied to cardiac computed tomography for noninvasive quantification of fractional flow reserve: scientific basis. J Am Coll Cardiol 2013; 61(22): 2233. 
[41] Mantero S, Pietrabissa R, Fumero R: The coronary bed and its role in the cardiovascular system: a review and an introductory singlebranch model. J Biomed Eng 1992; 14(2): 109.

[42] Itu L, Sharma P, Mihalef V, Kamen A, Suciu C, Lomaniciu D, (Eds.): A patient-specific reduced-order model for coronary circulation. 2012 9th IEEE international symposium on biomedical imaging (ISBI); 2012: IEEE.

[43] Itu L, Rapaka S, Passerini T, Georgescu B, Schwemmer C, Schoebinger M, et al.: A machine-learning approach for computation of fractional flow reserve from coronary computed tomography. J Appl Physiol 1985; 2016;121(1): 42.

[44] Fairbairn TA, Nieman K, Akasaka T, Norgaard BL, Berman DS, Raff G, et al.: Real-world clinical utility and impact on clinical decision-making of coronary computed tomography angiographyderived fractional flow reserve: lessons from the ADVANCE Registry. Eur Heart J 2018; 39(41): 3701.

[45] Lu MT, Ferencik M, Roberts RS, Lee KL, Ivanov A, Adami E, et al.: Noninvasive FFR derived from coronary CT angiography: management and outcomes in the PROMISE trial. JACC Cardiovasc Imaging 2017; 10(11): 1350.

[46] Curzen N, Rana O, Nicholas Z, Golledge P, Zaman A, Oldroyd K, et al.: Does routine pressure wire assessment influence management strategy at coronary angiography for diagnosis of chest pain?: the RIPCORD study. Circ Cardiovasc Interv 2014; 7(2): 248.

[47] Douglas PS, Pontone G, Hlatky MA, Patel MR, Norgaard BL, Byrne RA, et al.: Clinical outcomes of fractional flow reserve by computed tomographic angiography-guided diagnostic strategies vs. usual care in patients with suspected coronary artery disease: the prospective longitudinal trial of $\mathrm{FFR}(\mathrm{CT})$ : outcome and resource impacts study. Eur Heart J 2015; 36(47): 3359.

[48] Tonino PA, Fearon WF, De Bruyne B, Oldroyd KG, Leesar MA, Ver Lee PN, et al.: Angiographic versus functional severity of coronary artery stenoses in the FAME study fractional flow reserve versus angiography in multivessel evaluation. J Am Coll Cardiol 2010; 55(25): 2816.

[49] Patel MR, Nørgaard BL, Fairbairn TA, Nieman K, Akasaka T, Berman DS, et al.: 1-Year impact on medical practice and clinical outcomes of FFR(CT): the advance registry. JACC Cardiovasc Imaging 2020; 13(1 Pt 1): 97.

[50] Andreini D, Modolo R, Katagiri Y, Mushtaq S, Sonck J, Collet C, et al.: Impact of fractional flow reserve derived from coronary computed tomography angiography on heart team treatment decision-making in patients with multivessel coronary artery disease: insights from the SYNTAX III revolution trial. Circ Cardiovasc Interv 2019; 12(12): e007607.

[51] Pijls NH, De Bruyne B: Coronary pressure measurement and fractional flow reserve. Heart 1998; 80(6): 539.

[52] Driessen RS, Stuijfzand WJ, Raijmakers PG, Danad I, Min JK, Leipsic JA, et al.: Effect of plaque burden and morphology on myocardial blood flow and fractional flow reserve. J Am Coll Cardiol 2018; 71(5): 499.

[53] Nordgaard H, Swillens A, Nordhaug D, Kirkeby-Garstad I, Van Loo D, Vitale N, et al.: Impact of competitive flow on wall shear stress in coronary surgery: computational fluid dynamics of a LIMA-LAD model. Cardiovasc Res 2010; 88(3): 512.

[54] Corban MT, Eshtehardi P, Suo J, McDaniel MC, Timmins LH, Rassoul-Arzrumly E, et al.: Combination of plaque burden, wall shear stress, and plaque phenotype has incremental value for prediction of coronary atherosclerotic plaque progression and vulnerability. Atherosclerosis 2014; 232(2): 271.

[55] Chatzizisis YS, Baker AB, Sukhova GK, Koskinas KC, Papafaklis MI, Beigel R, et al.: Augmented expression and activity of extracellular matrix-degrading enzymes in regions of low endothelial shear stress colocalize with coronary atheromata with thin fibrous caps in pigs. Circulation 2011; 123(6): 621.

[56] Gijsen FJ, Mastik F, Schaar JA, Schuurbiers JC, van der Giessen WJ, de Feyter PJ, et al.: High shear stress induces a strain increase in human coronary plaques over a 6 -month period. EuroIntervention 2011; 7(1): 121.

[57] Slager CJ, Wentzel JJ, Gijsen FJ, Thury A, van der Wal AC, Schaar JA, et al.: The role of shear stress in the destabilization of vulnerable plaques and related therapeutic implications. Nat Clin Pract Cardiovasc Med 2005; 2(9): 456.

[58] Costopoulos C, Huang Y, Brown AJ, Calvert PA, Hoole SP, West $\mathrm{NEJ}$, et al.: Plaque rupture in coronary atherosclerosis is associated with increased plaque structural stress. JACC Cardiovasc Imaging 2017; 10(12): 1472.

[59] Falk E, Shah PK, Fuster V: Coronary plaque disruption. Circulation 1995; 92(3): 657.

[60] Farb A, Burke AP, Tang AL, Liang TY, Mannan P, Smialek J, et al.: Coronary plaque erosion without rupture into a lipid core. A frequent cause of coronary thrombosis in sudden coronary death. Circulation 1996; 93(7): 1354.

[61] Prati F, Uemura S, Souteyrand G, Virmani R, Motreff P, Di Vito $\mathrm{L}$, et al: OCT-based diagnosis and management of STEMI associated with intact fibrous cap. JACC Cardiovasc Imaging 2013; 6(3): 283.

[62] Stone PH, Saito S, Takahashi S, Makita Y, Nakamura S, Kawasaki T, et al.: Prediction of progression of coronary artery disease and clinical outcomes using vascular profiling of endothelial shear stress and arterial plaque characteristics: the prediction study. Circulation 2012; 126(2): 172.

[63] Gijsen FJ, Wentzel JJ, Thury A, Lamers B, Schuurbiers JC, Serruys PW, et al.: A new imaging technique to study 3-D plaque and shear stress distribution in human coronary artery bifurcations in vivo. J Biomech 2007; 40(11): 2349.

[64] van der Giessen AG, Wentzel JJ, Meijboom WB, Mollet NR, van der Steen AF, van de Vosse FN, et al.: Plaque and shear stress distribution in human coronary bifurcations: a multislice computed tomography study. EuroIntervention 2009; 4(5): 654.

[65] Kim HJ, Vignon-Clementel IE, Coogan JS, Figueroa CA, Jansen KE, Taylor CA: Patient-specific modeling of blood flow and pressure in human coronary arteries. Ann Biomed Eng 2010; 38(10): 3195.

[66] Douglas PS, Pontone G, Hlatky MA, Patel MR, Norgaard BL, Byrne RA, et al.: Clinical outcomes of fractional flow reserve by computed tomographic angiography-guided diagnostic strategies vs. usual care in patients with suspected coronary artery disease: The prospective longitudinal trial of FFRCT: outcome and resource impacts study. Eur Heart J 2015; 36(47): 3359-67.

[67] Nørgaard BL, Leipsic J, Koo B-K, Zarins CK, Jensen JM, Sand NP, et al.: Coronary computed tomography angiography derived fractional flow reserve and plaque stress. Curr Cardiovasc Imaging Rep 2016; 9(1). 
[68] Leipsic J, Yang T-H, Thompson A, Koo B-K, Mancini GBJ, Taylor C, et al.: CT angiography (CTA) and diagnostic performance of noninvasive fractional flow reserve: Results from the determination of fractional flow reserve by anatomic CTA (DeFACTO) study. Am J Roentgenol 2014; 202(5): 989-94.

[69] Min JK, Koo B-K, Erglis A, Doh J-H, Daniels DV, Jegere S, et al.: Effect of image quality on diagnostic accuracy of noninvasive fractional flow reserve: Results from the prospective multicenter international DISCOVER-FLOW study. J Cardiovasc Comput Tomogr 2012; 6(3): 191-9.

[70] Nørgaard BL, Gaur S, Leipsic J, Ito H, Miyoshi T, Park S-J, et al.: Influence of coronary calcification on the diagnostic performance of CT angiography derived FFR in coronary artery disease. JACC: Cardiovasc Imaging 2015; 8(9): 1045-55.

[71] Min JK, Leipsic J, Pencina MJ, Berman DS, Koo B-K, van Mieghem C, et al.: Diagnostic accuracy of fractional flow reserve from anatomic CT angiography. JAMA 2012; 308(12): 1237.

[72] Cook CM, Petraco R, Shun-Shin MJ, Ahmad Y, Nijjer S, Al-Lamee $\mathrm{R}$, et al.: Diagnostic accuracy of computed tomography-derived fractional flow reserve. JAMA Cardiol 2017; 2(7): 803.
[73] Nørgaard BL, Gormsen LC, Bøtker HE, Parner E, Nielsen LH, Mathiassen ON, et al.: Myocardial perfusion imaging versus computed tomography angiography-derived fractional flow reserve testing in stable patients with intermediate-range coronary lesions: Influence on downstream diagnostic workflows and invasive angiography findings. JAHA 2017; 6(8).

[74] Fairbairn TA, Nieman K, Akasaka T, Nørgaard BL, Berman DS, Raff G, et al.: Real-world clinical utility and impact on clinical decision-making of coronary computed tomography angiographyderived fractional flow reserve: lessons from the ADVANCE Registry. Eur Heart J 2018; 39(41): 3701-11.

[75] De Bruyne B, Hersbach F, Pijls NHJ, Bartunek J, Bech J-W, Heyndrickx GR, et al.: Abnormal epicardial coronary resistance in patients with diffuse atherosclerosis but "normal" coronary angiography. Circulation 2001; 104(20): 2401-6.

[76] Molony DS, Timmins LH, Hung OY, Rasoul-Arzrumly E, Samady H, Giddens DP: An assessment of intra-patient variability on observed relationships between wall shear stress and plaque progression in coronary arteries. BioMedi Eng OnLine 2015; 14(Suppl. 1): S2. 